January 2002

\title{
Defining the cultural milieu for implementing faculty practice in Pakistan
}

Michele J. Upvall

Aga Khan University

Zeenatkhanu Kanji

Aga Khan University, zeenatkhanu.kanji@aku.edu

Salma Jaffer

Aga Khan University

Khurshid Khowaja

Aga Khan University

Rubina Barolia

Aga Khan University

See next page for additional authors

Follow this and additional works at: http://ecommons.aku.edu/eastafrica_fhs_sonam

\section{Part of the Nursing Commons}

\section{Recommended Citation}

Upvall, M. J., Kanji, Z., Jaffer, S., Khowaja, K., Barolia, R., Amarsi, Y. (2002). Defining the cultural milieu for implementing faculty practice in Pakistan. International Journal of Nursing Practice, 8(6), 315-323.

Available at: $\mathrm{http}: / /$ ecommons.aku.edu/eastafrica_fhs_sonam/65 
Authors

Michele J. Upvall, Zeenatkhanu Kanji, Salma Jaffer, Khurshid Khowaja, Rubina Barolia, and Yasmin Amarsi 


\title{
RESEARCH PAPER
}

\section{Defining the cultural milieu for implementing faculty practice in Pakistan}

\author{
Michele J Upvall PhD FNP-C \\ Professor and Director, BScN Programme, School of Nursing, Aga Khan University, Karachi, Pakistan \\ Zeenatkhanu Kanji RN MScN \\ Doctoral Student, University of Alberta, Edmonton, Alberta, Canada \\ Salma Jaffer RN BScN \\ Assistant Manager, Nursing Services, Aga Khan University Hospital, Karachi, Pakistan \\ Khurshid Khowaja RN BScN \\ Director, Nursing Services, Aga Khan University Hospital, Karachi, Pakistan \\ Rubina Barolia RN BScN \\ Senior Instructor, School of Nursing, Aga Khan University, Karachi, Pakistan \\ Yasmin Amarsi RN PhD \\ Associate Professor and Associate Dean, School of Nursing, Aga Khan University, Karachi, Pakistan \\ Accepted for publication May 2002
}

Upvall MJ, Kanji Z, Jaffer S, Khowaja K, Barolia R, Amarsi Y. International Journal of Nursing Practice 2002; 8: 315-323

Defining the cultural milieu for implementing faculty practice in Pakistan

Faculty practice can promote a collaborative partnership mutually beneficial to both nursing education and service. However, little is known about its implementation in developing countries. The purpose of this study was to explore the potential for introducing faculty practice within the cultural milieu of Karachi, Pakistan. Focus groups of nursing faculty, staff and students were conducted in various settings: government, semigovernment and private institutions to elicit the data. Data analysis revealed that a more comprehensive definition of faculty practice is needed that will provide the foundation for a culturally acceptable model of faculty practice in Pakistan. Hierarchy dominates the current cultural milieu and must be addressed before faculty practice can be implemented.

Key words: faculty practice, focus groups, nursing education, Pakistan.

\section{INTRODUCTION}

The concept of faculty practice is relatively unknown in Pakistan. There are no requirements by the nursing coun-

Correspondence: Professor Michele J Upvall, Aga Khan University, PO Box 3500, Karachi 74800, Pakistan.Email: michele.upvall@aku.edu cil or other institutions in the country for faculty to maintain clinical competency, or even be present with students in the clinical area with the exception of one private school of nursing. Therefore, the current cultural milieu of nursing education in Pakistan promotes few opportunities for interaction between nursing faculty and nursing 
staff in hospitals. Students receive the theory component of their courses from faculty and clinical supervision from nursing staff. The majority of nursing faculty neither provide direct patient care services within the hospital nor do they accompany students in the hospital wards.

The context of nursing education in Pakistan may be similar to that of other developing countries. There is a dearth of research regarding the role of faculty and expectations of clinical competency. Nahas described nursing education in cosmopolitan Hong Kong noting that nursing faculty, as in Pakistan, are not responsible for clinical supervision of students. ${ }^{1}$ However, she advocated nursing faculty maintaining clinical credibility, or competence, as faculty are accountable for students' learning regardless of the classroom or clinical setting. Faculty must be prepared to answer questions from students and relate theory to clinical situations. The purpose of this study was to explore the potential for introducing faculty practice to schools of nursing in Pakistan, specifically within the megapolis of Karachi, a port city in the province of Sindh. Karachi was chosen because it is the largest city in Pakistan with many hospitals and schools of nursing.

Research questions guiding this study were:

1. What is the current definition of faculty practice articulated by nursing faculty, staff and students?

2. How can faculty practice be implemented in schools of nursing?

3. What are the perceived challenges of implementing faculty practice?

\section{Perspectives of faculty practice in developed countries}

As early as the 1960s, administration from the University of Florida School of Nursing recognized that the separation between nursing education and service could be ultimately detrimental to student learning. However, expert nurses would be in an optimum position for teaching students clinical decision-making skills.

Since the 1970s, nurse educators have developed organizational models to facilitate nursing education-service collaboration. ${ }^{2,3}$ These models include the:

- Unification Model: nursing hospital administrators have positions as educators. For example, the Dean of a School of Nursing is also a Director of Nursing Services.

- Collaboration Model: a percentage of time is given to both education and service through a system of joint appointments.
- Dyad Model: faculty are paired with a clinical nurse specialist and joint projects related to education, practice and research are completed.

- Research Joint Appointments: nursing service establishes a Director of Nursing Research who also works with a School of Nursing. Utilization of research findings into practice is the result.

- Integrated Model: both faculty and a graduate level student share the responsibility for patient care.

- Entrepreneurial Model: faculty designs their own practice as part of their faculty responsibilities. Faculty may also negotiate to use their practice site as a research and teaching site as well.

Development of organizational models for faculty practice requires a conceptual definition of faculty practice. Definitions from prominent nursing organizations have been proposed as follows:

\section{Faculty practice includes all aspects of the delivery of nursing service through the roles of clinician, educator, researcher, consultant and administrator. ${ }^{4}$ \\ Practice scholarship encompasses all aspects of the delivery of nursing service where evidence of direct impact in solving health-care problems or in defining the health problems of a community is presented. $^{5}$}

Such definitions of faculty practice allow for a variety of interpretations. The scope of these definitions allow faculty to define their own practice, regardless of setting.

For example, faculty practice may be clinical supervision of students, reading current nursing literature and applying it to the classroom, applying research findings to clinical practice, or providing direct patient care. The few research studies relating to the evaluation of faculty practice demonstrate the need for a clear definition of faculty practice readily translated into a particular clinical setting. ${ }^{3,6}$ Barger asks the question, 'Are we able to engage in evolving collaborative relationships that are both more interdisciplinary and more extensive without feeling that our unique contributions are being threatened?' . ${ }^{7}$

This thought-provoking question implies the need for original thinking for the development of faculty practice. Krafft emphasizes the need for a definition of faculty practice that can be shared within the context of a particular faculty. ${ }^{8}$ The definition of faculty practice will then influence policies and impact issues at the university, school of nursing, and faculty levels. 
University issues include how scholarship is defined, the need to develop a reward system for faculty practice, and an assessment of risks and benefits of faculty practice. For example, faculty may feel overworked and experience burnout if they are expected to teach, conduct research, and maintain practice. Rewards and adjustment of teaching loads may then become necessary. Issues at the school of nursing level include using faculty practice as a method to ensure clinical relevance to the curriculum and sharing of faculty expertise with nursing services; faculty practice as a way to meet the need for revenue generation within the school, which may affect availability for students; and incentives for faculty not choosing faculty practice, but instead carrying a heavier teaching load. Finally, faculty issues include the personal satisfaction that faculty may receive in a collaborative role; service agreements that revenue may or may not be given directly to the individual faculty, but may go to the school; and of overriding concern, time management to prevent frustration from work overload and dealing with role changes.

There are consistent findings from studies related to role changes and faculty practice. Lambert and Lambert compared role stress with psychological hardiness. ${ }^{6}$ The researchers suggested that as psychological hardiness increases, the perception of role stress decreases. A belief in a lack of control in life and decreased number of hours engaged in active teaching was the best prediction of role stress in groups of faculty either engaged in practice or only teaching. This finding suggests that nursing faculty must have a sense of being in control in their lives and may be in more control within a teaching context rather than doing research or in faculty practice. Faculty engaged in practice also experience greater role stress as a sense of control in life decreases.

Faculty practice was considered to be part of scholarship in a study conducted by Tolve. ${ }^{9}$ Faculty practice was highly valued by deans and faculty even though it may not be an expectation of faculty. Respondents from the survey perceived role conflict and fragmentation as the major advantage for faculty practice if added to other roles. Faculty expressed the need for release time or academic credit for faculty practice. Therefore, more creative and integrated models of scholarships are necessary for recognizing the value of faculty practice.

Novak related her personal story of beginning a faculty practice. ${ }^{10}$ She shared her experience of role strain as she tried to balance the expectations of both academia and service. Recommendations for a successful practice included proactive communication between academia and service to prevent misunderstandings regarding workload, recognizing role ambiguity as faculty practice credibility is being established, and making a detailed contract that clearly outlines expectations, including the cost of faculty practice.

All models of faculty practice have advantages and disadvantages. It is clear that faculty practice in nursing in developed countries is desirable but is not without considerable constraints. Patients, students, nursing services, and faculty can all benefit from nurse educators' willingness to maintain clinical competence. Collaborative research effort is another benefit of faculty practice. In addition, expert clinical nurses can role model their skills, mentoring students and influencing the next generation of nurses. ${ }^{2}$ Failure when implementing faculty practice can occur for a variety of reasons, such as lack of commitment and motivation of faculty, time constraints, lack of reward structure, ambiguous definitions of faculty practice and, most importantly, role stress. ${ }^{8}$ Collaboration between faculty, academia and service institutions prior to the development of faculty practice is crucial to clarify expectations if faculty practice is to be a success. Role conflict is an expected reaction to bridging the academic and the hospital environments and should be viewed as a challenge. ${ }^{11}$

\section{Overview of nursing education in Pakistan}

Pakistan is an Islamic country consisting of a variety of ethnic groups throughout its four provinces and federally administered areas. There is a ratio of four physicians for every nurse, and health-care issues appear almost insurmountable. There are over 132 million people in the country and the population continues to grow with Pakistan having one of the highest fertility rates (5.6\%) in comparison to other surrounding Asian countries. ${ }^{12}$

Nursing education in Pakistan is characterized by 3year diploma programs with a total of 77 schools of nursing: 53 government; one semigovernment; five army; and 18 private. These students must successfully complete provincial nursing board examinations throughout the programme in order to receive their license to practice as a Registered Nurse (RN). Students may also take an additional year of midwifery of post-basic educational to become a Registered Midwife. The 19 public health schools (all government) provide a 2-year educational programme to prepare Lady Health Visitors (LHV), who 
are also qualified midwives, to work in primary healthcare settings (NI Durrani, pers. comm., February 2000). Other programs include the Diploma in Ward Administration (DWA) and Diploma in Teaching Administration (DTA) each lasting 1 year. In the past, the DWA was required before completing DTA, but now RNs can complete the DTA after completing another 12 months specialization such as intensive care, paediatrics, community health or anaesthesiology. A DTA is required of nursing faculty who are teaching in government schools of nursing. However, no further continuing education or clinical practice is required beyond the DTA.

The first degree programme at a post-basic level was implemented at a private university in 1988. At the end of the 2-year curriculum students receive a Bachelor of Science in Nursing $(\mathrm{BScN})$. At present, a post-basic $\mathrm{BScN}$ programme is offered at two private universities and one government university. Also post-basic studies in three non-nursing subjects are offered by several universities in the public sector and completion of these courses lead to a BSc degree. ${ }^{13,14} \mathrm{~A} 4$-year undergraduate programme was initiated in 1997, again at a private university. The first Master of Science in Nursing programme in Pakistan with an advanced nursing practice focus began in October 2001.

\section{METHOD}

Use of focus groups was considered the most appropriate method for data collection. The underlying assumption of focus groups is that perceptions develop through interaction with others, not in isolation. In this method, a group of 8-10 people with similar backgrounds, roles and interests are interviewed to uncover their attitudes and perceptions towards the topic under investigation. ${ }^{15}$

Focus groups have many advantages in comparison to individual interviews. Data can be obtained more quickly from a group of individuals at a lower cost. The researcher still maintains direct contact with participants and probing of responses can occur. Also, focus groups allow the members to react to each other, promoting a synergistic effect. Finally, focus groups can be used in many different settings with any homogenous group of people. ${ }^{16}$ They have been successfully used in other research studies in Pakistan. ${ }^{17}$

A semistructured interview form was used to guide each focus group. All interviews were audio-taped and lasted 30-90 min. Approval to conduct the study was given by a university Human Subjects Protection Com- mittee and hospital nursing and medical superintendents. Consent forms were provided to each participant and an explanation of the study was given prior to interviewing.

A total of 15 focus groups were conducted in five hospitals having a school of nursing in Karachi, Pakistan. Three focus groups were completed in each setting comprising a group of faculty, senior nursing staff, and students from year 1-3 of their education. A cross-section of hospitals and their respective schools of nursing were chosen to elicit their perception of faculty practice and to determine any differences between institutions. Two hospitals and schools represented the government sector (one federal and one provincial government institution), two private institutions, and one considered to be semigovernment. The total number of participants included $37 \mathrm{fac}-$ ulty, 42 senior nursing staff and 48 students $(n=127)$. The smallest focus group consisted of four faculty members from a private institution and no focus group exceeded 11 participants.

Urdu was the primary language used during the interviews. English could be understood and spoken by the participants, but at different levels. Therefore, the indigenous language of Urdu was utilized. Researchers conducting the focus groups were all Pakistani nurses fluent in Urdu and English. However, all interviews were translated into English during the transcription process. Data was then coded and compared between each focus group. Credibility of the coding was ensured by having all research members code the data individually and as a group. Coding the data facilitated categorization of responses. Comparison was accomplished through use of Ethnograph 4.0, a software package to facilitate organization of the coded categories for interpretation by the researchers.

\section{RESULTS Defining faculty practice}

Faculty practice as defined by direct, 'hands-on' patient contact is relatively unknown in Pakistan. Few of the participants, faculty, nursing or students could articulate a definition of faculty practice of faculty working independently, separate from the teacher role. Regardless of setting, participants focused on supervision of students in the clinical area as faculty practice. However, their definitions could be considered consistent with the broad definitions given by the National Organization of Nurse Practitioner Faculties ${ }^{4}$ and The American Association of Colleges of Nursing. ${ }^{5}$ 
To me, nursing faculty practice means that whoever is a nurse should stay in the ward and whatever students are doing as the practical, she should match it against her own checklist. So that she can check whether students are following what they are taught in theory class.

When faculty go to the wards they will deal with students. They will do clinicals. They will provide guidelines to the students. So they will be dealing with students. That's what I understood.

Faculty practice means students working under the teacher's supervision.

Preparation for theory and practicals of any subject is called faculty practice.

An alternative definition of faculty practice was suggested to participants by the researchers after participants provided their own definition. This definition excluded student supervision, focusing on faculty having their own assignment in the ward as a staff nurse. On the surface, participants believed this to be a positive role for faculty by stating:

It gives you a feeling of integration. They [service] don't feel that you are working in isolation... This practice will give us a sense of association with each other.

If faculty comes herself and if she works as staff then she will come to know how many problems there are.

There are many things that teachers have forgotten since they are out of practice and they don't demonstrate it in front of students. So, it's important that they should go and learn in wards.

Participants also felt that faculty practice would be perceived positively by the public and other care providers. However, participants in nursing service viewed faculty practice as having additional staff, which would only benefit patients.

Patients will feel good that a faculty is there to take care of them. These days there are very few people in the wards so the patients do not get too much care as they used to get previously.

They [physicians] will feel that there is an addition of one staff in our ward and she should work.

Nursing staff believed that patients might be hesitant at first in accepting a faculty as a provider, but they are willing to introduce the faculty and reassure the patient.
If we take our faculty to the patients and introduce them that she is also one of us and she will be working with us... maybe patients will not hesitate that much and then they will be satisfied.

Changes in health care, especially new technology and medications was the reason most often cited for implementing faculty practice.

In our time, there were fewer things to learn, but new technology and research is here. There are new medicines... what are their sideeffects and what are their advantages and disadvantages? We want to learn these things.

Competency in nursing care skills was also thought to be an important outcome of faculty practice. Participants believe that faculty should be knowledgeable in all levels of skills from making beds to using ventilators and inserting nasogastric tubes.

\section{Making faculty practice possible}

Consensus could not be reached as to how often faculty should be engaged in practice. Responses ranged from $2 \mathrm{~h}$ per week to 2 months per year. Some believed that faculty should have a choice or even spend an hour a day going to the wards when they are off-duty and not teaching. Time for faculty practice was contingent upon where faculty would practice and their particular objectives. Faculty either wanted to set their own objectives or have the school of nursing administration determine the objectives rather than hospital administration.

If our objectives are not fulfilled... then what is the use of going over there?

Our objective should be set by the school and not by administration.

If I go to a ward or ICU, I will meet the ward in-charge and tell him that I am here for faculty practice and for my improvement and I want to learn these things. It is not necessary that I take a patient who is on a ventilator or I take a patient that is going to be out from ICU. I would like to see overall ... whatever I want to learn I will pick from the patients.

We should go to the wards, but one should not work like staff... we should work for our own knowledge.

Practical ways to implement a successful faculty practice included: 'faculty of one hospital should go to another hospital and practice there'. 
One way to introduce the idea of faculty practice to faculty and offer a reward was through short courses or workshops. Completion of such courses would be rewarded by a special certificate:

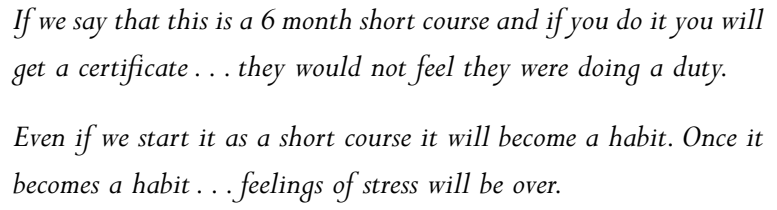

Some faculty felt that faculty practice could only be acceptable if required by the governing body for nursing, the Pakistan Nurses Council.

Staff nurses were willing to provide an orientation to faculty to increase the potential of success of faculty practice, but many had their doubts about faculty having their own assignment.

Since she does not have practice but has studied about it then they should be under supervision . . . so they can get used to the routine.

If a faculty comes to NICU, she would not be allowed to work independently ... Every new person cannot be explained [about the patient]. So it is better to keep faculty under supervision. Even when staff from [other] wards come we don't leave them independently.

Participants reflected upon how to evaluate faculty performance if providing direct patient care. However, with the exception of students who wanted to evaluate faculty themselves, most participants believed that evaluation should occur and be done by a nurse who would be in a more senior position to the faculty member.

I think senior people, like a matron, should come and check them ... as they are senior faculty and we are junior, they might not feel better if we do their evaluation.

Staff in-charge or unit in-charge will do the faculty evaluation. If a faculty is making some mistakes, it is also the responsibility of the staff in-charge to guide them.

Participants identified a variety of methods for evaluation including observation by staff nurses, review of nursing notes and report registers, use of 'mini-tests' on the ward, checklists, and verbal feedback by nursing staff.

\section{Potential barriers to faculty practice}

The categories of faculty status and maintaining respect within the hierarchy of health care was evident in the focus groups and could easily impact the success of faculty practice.

If she [faculty] is coming for checking then she should tell us [staff] then she would be above us. If she is coming to learn then she would be coming under us.

If we [staff] do any mistake she [faculty] will correct us. There are some procedures that we might be doing wrong. As she knows more than us, she can guide us.

One faculty member gave an example of how she was called to the ward late one night when 20 people were admitted at once. She stated that she was not there to supervise, but care for patients. She also noted that both nurses and physicians were providing good care and she attributed this to:

Respect and fear, they think that teachers might report to the higher-ups.

Such comments again indicate a hierarchy with faculty perceived as having power to report unacceptable caregiving to hospital administration.

Some faculty believed that both students and staff will lose respect for them if they practice in the wards. The attitude of continually learning was absent as they stated:

Most of the students will have a negative reaction. They will say that the tutor is learning herself. . . what will she teach us?

Right now they [students] don't know what we know and what we don't know. When a third year student is handling a ventilator, suppose I can't do it? If I go and ask a student how to operate it then it should be embarrassing for me... there will be no respect for me in my students.

If we [faculty] want to learn something then we have to bring ourselves to a level lower than them.We have to tell them that we are totally blank and we have nil knowledge and can you please guide us. Then they will guide us.

If I go as a supervisor or an instructor or as a faculty member and if I say that I am a faculty member and you teach me they will say we don't have time. If we try to be friendly with them and if we come to their level and want to learn then they will help us. But you have to come to that level. 
I feel shy because here I teach my students and when I go there my students will work with me. Whatever they are doing, I would be doing the same work. That is why I would feel a little bit embarrassed.

Government students in particular hold strong views about status and faculty practice. To these students, faculty are beyond the everyday care-giving levels of staff nurses. Traditional beliefs of demonstrating respect such as standing in the presence of someone with more status, unacceptability of working at the same level, and assuming one's 'superior' has nothing more to learn was evident in their comments.

Clinical [supervision] should not be for instructors. This is a responsibility of a ward sister.

When we [students] go to the wards and our seniors [staff] are there we stand up to give them respect. How can it be possible that our seniors [faculty] are with us and they are doing work?

We will give her [faculty] respect and we will obey her orders, but we can't give her orders.

The work that she is going to do in the ward she is already teaching that in a class... when she knows everything then I don't think she should go and work in a ward.

Nursing staff believed that the high level of regard for instructors could instil a sense of fear in the students that would motivate students and also themselves to provide better nursing care. Although this could be of benefit for implementing faculty practice, the idea of using fear as a teaching strategy may ultimately be considered a barrier, hindering the potential for collegial student-faculty relationships.

When a faculty is present then we will think that she is more senior than us and we will try not to make any mistake in front of them. We will be punctual.

It will make a lot of difference faculty practice. The student will take her work more seriously and she will work under pressure.

As expected, the potential for an increased workload and shortages of both nursing staff and faculty created many anxieties among all participants. Students felt that:

When there is more workload and she is stressed then neither can she teach us properly nor can she practice her own skills in the ward.
Our teachers have three subjects right now and she has a lot of burden... how can she go and work in a ward?

Faculty were afraid that the students will be affected by faculty practice and they will be taken advantage of by hospital administration.

If the staff is absent and if they ask us that since we are doing clinical practice so we should work. If we go and work late, ... then our school will suffer and our students will be neglected.

They will say you are required in this ward today and this will happen frequently.

We have to change our infrastructure ... they have to increase staff members. They have to provide transport.

Despite the possible barriers for implementing faculty practice, there was a strong willingness to at least consider the possibility. Timing and preparation are crucial to the success of faculty practice. As one faculty member summarized:

Everything is possible if we work, but right now we are not mentally prepared for it.

\section{DISCUSSION}

Participants were unsure of a definition of faculty practice except for perceiving it as clinical supervision of students. Once researchers suggested a definition of faculty practice as direct patient care, the study participants responded positively believing that patients and other health-care providers could benefit from interaction with faculty. Faculty would then maintain their clinical skills and keep abreast of advances in technology. Faculty practice faces many challenges in a system where distinct boundaries and hierarchy characterize the cultural milieu of nursing education. The thought of crossing these boundaries created fear in all groups affected, including students.

Students are afraid that their teachers will not give enough time for theory in the classroom. Also, the current distance between instructor and student in clinical settings highlights a hierarchical system, masked by espousing respect. Faculty are afraid that their learning needs and objectives will not be met and they will be used to meet staffing shortages in the hospital. Again, these are issues related to hierarchy. As a faculty member, nursing staff thought that faculty have a great amount of knowl- 
edge that should be unquestioned. Being challenged would indicate a downward movement in the hierarchy with loss of respect from both students and staff. Staff fear that a faculty member will look at them more critically.

Attitudes of 'us versus them' are prevalent, characterized by a strong system of hierarchy. This was more evident in the government institutions, but private and semigovernment hospitals and schools of nursing experienced this attitude to some degree as well. Such attitudes can create major obstacles for implementing a successful model of faculty practice. From a faculty perspective, a successful faculty practice model would include faculty taking control by setting their own objectives, going to a different hospital setting from the one in which they taught and making faculty practice a requirement by the Pakistan Nursing Council. Staff nurses would be willing to assist in the process by providing faculty an orientation to the hospital wards, but still wanted to exercise control over faculty by not allowing them to have their own patient assignment. In addition, nursing staff and faculty themselves wanted to maintain a hierarchical system by having senior staff or nursing administration evaluate faculty performance. MacPhail emphasized that changes in both academic and service organizations must occur before faculty practice can be fully implemented, ${ }^{3}$ and this appears to apply to Pakistan as well. Specifically, decentralization, restructuring, redefining roles and relationships, and changing expectations of colleagues and patients will be necessary for implementing a successful model of faculty practice. Nursing leadership is also required and the numbers of faculty involved in practice should increase. $^{3}$

MacPhail also reported that successful models of faculty practice were the result of planned change. ${ }^{3}$ Institutions in Pakistan considering faculty practice should take note of the need for planning and open communication between the organizations. Creativity will be required to integrate systems as well as a willingness to share control between faculty and staff. ${ }^{7}$

Strategies to improve integration that should be considered when developing a faculty practice model for Pakistan include: cognizance of the 'us and them' concept $;{ }^{18}$ faculty maintaining visibility in the clinical area by listening to units reports, making rounds together with other nurses, and offering help during busy times; ${ }^{19}$ and, finally, defining clinical expertise of faculty, which may or may not include direct patient care. ${ }^{20}$ Nursing education may also need to be redefined to include student supervision in the clinical area by faculty.

\section{CONCLUSION}

Faculty practice is not as well understood or accepted in a developing country such as Pakistan as it may be in more developed countries. The cultural milieu of nursing in Pakistan is dominated by the concept of hierarchy. Hierarchy is manifested by nurses' perception of their position, their role and relationships to other nursing roles. For example, staff nurses accept, even appear to desire, directions from administration. Nursing faculty are perceived to be of higher rank than nurses in hospital service, while students who provide the majority of nursing care in government and some private hospitals have the least amount of power and stature.

The situation in Pakistan mirrors the historical development of nursing and nursing education in developed countries. Educational programmes at the undergraduate and graduate level are currently being introduced in Karachi. These programmes are confined to only a few private institutions, but it is feasible to imagine government schools of nursing evolving from diploma to baccalaureate education within the next 15-20 years. Nursing faculty practice may then emerge in government hospitals and educational institutions if private institutions set the example. It will be necessary for nursing faculty in private settings to extend their practice into government settings where they can be role models. Many challenges will exist: working with few human and material resources in the hospital; relating to physicians who may undervalue the contribution of nurses; fears of being subsumed into a service role while maintaining an identity as faculty; and, most importantly, redefining nursing faculty practice in a way that will improve patient care.

\section{REFERENCES}

1 Nahas V. Maintaining clinical credibility as a nurse teacher in a post-graduate tertiary specialization program. Clinical Nurse Specialist 2000; 14: 184-188.

2 Hutelmyer C, Donnelly F. Joint appointments in practice positions. Nursing Administration Quarterly 1996; 20: 71-79.

3 MacPhail J. Collaboration between nursing education and nursing practice for quality nursing care, education, and research. In: Kerr J, MacPhail J (Eds). Canadian Nursing: Issues and Perspectives. St. Louis: CV Mosby, 1996; 334-349.

4 National Organization of Nurse Practitioner Faculties. Faculty Practice Models. Washington, DC: National Organization of Nurse Practitioner Faculties, 1993. 
5 American Association of Colleges of Nursing. Position Statement on Defining Scholarship for the Discipline of Nursing. Washington, DC: American Association of Colleges of Nursing, 1999. Available from: http: / /www.aacn.nche.edu/publications/ positions/scholar.htm

6 Lambert C, Lambert VA. Relationships among faculty practice involvement, perception of role stress, and psychological hardiness of nurse educators. Journal of Nursing Education 1993; 32: 171-179.

7 Barger S. Partnerships for practice: a necessity in the new millennium. Journal of Profession Nursing 1999; 15: 208.

8 Krafft S. Faculty practice: why and how. Nurse Educator 1990; 23: 45-48.

9 Tolve CJ. Nursing scholarship: role of faculty practice. Clinical Excellence for Nurse Practitionuers 1999; 3: 28-33.

10 Noval C. The serendipity of faculty practice. Nurse Educator 1999; 24: 42-44.

11 Donnelly GF, Warfel W, Wolf ZR. A faculty practice program: three perspectives. Holistic Nursing Practice 1994; 8: 71-80.

12 World Bank. Entering the 21st Century:World Development Report 1999/2000. Oxford: Oxford University Press, 2000.
13 Amarsi Y. Key stakeholders perceptions of nursing human resource development in Pakistan. Unpublished dissertation. McMaster University, Hamilton, Canada, 1998.

14 Kanji Z, Stanley G. Survey of Nurses in Pakistan with University Degrees. Unpublished project report. The Aga Khan University, Karachi, Pakistan, 2000.

15 Morse J, Field PA. Nursing Research: the Application of Qualitative Approaches. London: Chapman \& Hall, 1996.

16 Stewart DW, Shamdasan PN. Focus Groups: Theory and Practice. Newbury Park: Sage, 1990.

17 Upvall M, Rehmatullah S, Hashwani S, Khan S, Husain P, Jan R. The implementation of a Bachelors of Science in Nursing Education in Pakistan. Nursing and Health Sciences 1999; 1: 221-228.

18 Glossop D, Hoyles A, Lees S, Pollard C. Benefits of nurse teachers returning to clinical practice. British Journal of Nursing 1999; 8: $394 \quad 400$.

19 Mateo M, Fahje C. The nurse educator role in the clinical setting. Journal for Nurses in Staff Development 1998; 14: 169 175.

20 Burke L. Teachers of nursing: presenting a new model of practice. Journal of Nursing Management 1997; 5: 295-300. 